\title{
Educação Ambiental como campo de conhecimento: a contribuição das pesquisas acadêmicas para sua consolidação no Brasil
}

\author{
Jorge Megid Neto ${ }^{1}$
}

Resumo: Este artigo discute a contribuição da produção acadêmica no âmbito da pósgraduação para a consolidação e desenvolvimento do campo de conhecimento em Educação Ambiental no Brasil. Apresenta algumas características e tendências do conjunto de 2.641 dissertações e teses defendidas no período de 1981 a 2008. Também apresenta a estrutura, propósitos e alguns dados preliminares do projeto interinstitucional "A Educação Ambiental no Brasil: análise da produção acadêmica (dissertações e teses)", em desenvolvimento por Grupos de Pesquisa vinculados à Unicamp, UNESP-Rio Claro, USP-Ribeirão Preto e UFSCar e no qual se pretende um amplo levantamento e estudo da produção científica e acadêmica na área.

Palavras-chave: Pesquisa em Educação Ambiental, Estado da Arte, Educação Ambiental.

Abstract: This article discusses the contribution of academic research carried out through postgraduate programs in Brazil for the development and consolidation of the field of Environmental Education in this country. It presents some features and trends of the 2641 dissertations and theses produced in the period 1981 to 2008. Moreover, this work describes the structure, purposes and some preliminary data from the project "Environmental Education in Brazil: analysis of academic production (theses and dissertations)", which is under development by research groups linked to State University of Campinas, State University of São Paulo - Rio Claro Campus, University of São Paulo - Ribeirão Preto Campus, and Federal University of São Carlos. The main aim of the project is to establish the state of the art of Environmental Education in Brazil and to generate a database that will benefit further analytical studies on the academic production in this area.

Keywords: Environmental Education Research, State of the Art, Environmental Education.

${ }^{1}$ Licenciado em Física, Mestre e Doutor em Educação. Professor do Depto. de Ensino e Práticas Culturais. Faculdade de Educação Universidade Estadual de Campinas Unicamp. Contato: Av. Bertrand Russell, 801 - Cidade Universitária Zeferino Vaz CEP 13083-865 - Campinas - SP. E-mail: megid@unicamp.br 
O estatuto de um novo campo de conhecimento científico é alcançado a partir de alguns critérios, os quais, a depender dos referenciais teóricos, podem variar em um ou outro atributo. Para Cachapuz et al. (2005), por exemplo, o desenvolvimento de um novo campo de conhecimento está geralmente associado às seguintes condições: a existência de uma problemática relevante, capaz de despertar interesse e esforços para seu estudo; o caráter específico dessa problemática, que impede seu estudo por outro corpo de conhecimento já constituído; e a existência de condições externas favoráveis, como o contexto sociocultural e os recursos humanos específicos.

É inegável que o campo da Educação Ambiental (EA) no Brasil e em outros países atende largamente a essas condições. Traz uma problemática - a questão ambiental, sua dinâmica de transformação, sua degradação, a sustentabilidade ambiental, entre outros aspectos - de alta relevância e discutida em âmbito mundial há mais de cinco décadas, intensificando-se seu estudo e preocupações cada vez mais, em virtude de um contexto sociocultural, político, econômico e ideológico a exigir medidas globais e imediatas para o tratamento das questões ambientais. Nesse contexto, vemos difundirem-se no Brasil os cursos de formação profissional em áreas direta ou indiretamente vinculadas à Educação Ambiental ou à temática ambiental, em nível de formação profissional técnica ou tecnológica, de graduação e de pós-graduação.

No âmbito da pós-graduação, devemos lembrar que sua institucionalização no Brasil ocorreu nos anos 1960, especialmente após a Reforma Universitária, com a Lei Federal no 5.540, de 1968, podendo-se considerar ainda um fenômeno recente quando comparado a outros países com tradição de vários séculos no âmbito universitário e da pesquisa acadêmica. $\mathrm{Na}$ realidade, atividades de pós-graduação stricto e lato sensu já se manifestavam no país desde a década de 1930, muito embora somente com a 1a Lei de Diretrizes e Bases da Educação Nacional (Lei Federal no 4.024/61) tenham se apresentado as primeiras referências aos cursos de pós-graduação na legislação educacional.

No campo educacional, o primeiro curso de pós-graduação no país foi criado na PUC-RJ - Mestrado em Educação - em 1965. Todavia, a pesquisa científica brasileira no campo educacional é anterior a isso. Vem se consolidando como área de investigação, fora do estatuto da pós-graduação, desde a década de 1940 com a criação do Instituto Nacional de Estudos Pedagógicos (Inep) e, posteriormente, com o Centro Brasileiro de Pesquisas Educacionais (CBPE), em 1956, acompanhado de seus Centros Regionais (MEGID NETO, 1999).

A partir de meados da década de 1960, a pesquisa educacional toma impulso com a institucionalização dos mestrados em Educação. Ocorre uma expansão rápida e intensa dos cursos, a ponto de, somente na primeira metade 
dos anos 1970, terem sido criados 65\% dos programas de mestrado na área, entre aqueles em funcionamento até 1992. Os primeiros cursos foram implantados na: PUC-RJ, 1965; PUC-SP, 1969; UFSM, 1970; UFF, UFMG e USP, em 1971 (FÁVERO, 1993).

Com o desenvolvimento dos programas de pós-graduação em Educação, surgem as primeiras dissertações de mestrado no campo da Educação Ambiental, defendidas em 1981: quatro dissertações de mestrado, duas na USP, uma na UFMG e outra na UFRN. A primeira tese de doutorado defendida na área data de 1990, no programa de Doutorado em Educação da Faculdade de Educação da USP (ver CARVALHO, 1990).

Desde então, a área de pesquisa em Educação Ambiental cresceu fortemente, estimando-se cerca de 3.000 dissertações e teses até 2009. Comparando-se com outras áreas do campo educacional (escolar e não escolar) cujo desenvolvimento da pesquisa no âmbito da pós-graduação inicia-se bem antes (final dos anos 1960), as pesquisas em EA apresentam resultados até mesmo superiores do ponto de vista quantitativo. Como exemplo, trazemos o campo de pesquisa em Educação em Ciências no Brasil, cujas primeiras teses e dissertações defendidas datam de 1971, portanto, dez anos antes que as primeiras produções em EA, tendo sido defendidos até 2009 cerca de 2.800 trabalhos.

Toda vez que um campo de conhecimento alcança uma produção quantitativa significativa, surge a necessidade de empreender estudos sistemáticos dessa produção, visando o conhecimento mais adequado das suas características e tendências, além de favorecer sua ampla e adequada divulgação. Surgem assim as "pesquisas do estado da arte", também denominadas pesquisas do "estado do conhecimento" ou do "estado atual do conhecimento".

Essas pesquisas buscam inventariar, sistematizar e avaliar a produção em determinada área do conhecimento, o que implica a identificação de trabalhos produzidos na área; a seleção e classificação dos documentos segundo critérios e categorias estabelecidos em conformidade com os interesses e objetivos do pesquisador; a descrição e análise das características e tendências do material; e a avaliação dos seus principais resultados, contribuições e lacunas. A partir disso, remetem para a realização de metapesquisas e estudos que aprofundam aspectos específicos e interessantes do conjunto da produção e também sinalizam a realização de novas investigações, seja para esclarecer ou aprofundar algum aspecto específico, seja para dar tratamento a questões ainda não abordadas. Ou seja, as pesquisas do estado da arte têm um caráter de revisão bibliográfica e, ao mesmo tempo, de especulação futura e de iluminação de novos caminhos para o campo em questão. Enfim, trata-se de conhecer o que se sabe sobre determinado campo do conhecimento, bem como o que se deve ou se precisa saber para fazer 
avançar o campo, passado e futuro, com vistas ao planejamento e desenvolvimento do estado presente.

Ainda fazendo uma comparação entre os campos de pesquisa em Educação em Ciências e em Educação Ambiental, pesquisas de revisão bibliográfica têm ocorrido com certa frequência no primeiro, principalmente nos anos 2000, enquanto ainda são raras no segundo. O Grupo de Pesquisa FORMAR-Ciências (Estudos e Pesquisas sobre Formação de Professores da Área de Ciências), da Faculdade de Educação da Unicamp, vem se dedicando desde meados dos anos 1980 a estudos de mapeamento, descrição e análise da produção científica e acadêmica brasileira no campo da Educação em Ciências. Vários estudos foram realizados até o momento: Fernandes, 2009; Fracalanza, 1993; Megid Neto, 1990, 1999; Nogueira, 2008; Rink, 2009; Santos, 2001; Silva, 2004; Teixeira, 2008.

O grupo também possui como uma de suas linhas de pesquisa Educação Ambiental e Ensino de Ciências, tratando das questões ambientais na perspectiva educacional e interdisciplinar, e em especial nas suas articulações históricas com o Ensino de Ciências. Desse modo, também tem investido desde meados dos anos 2000 em estudos do tipo estado da arte no campo da EA. O primeiro projeto nessa linha teve início em 2003, sob o título "O que sabemos sobre a Educação Ambiental no Brasil: análise da produção acadêmica”, sendo coordenado pelos professores Hilário Fracalanza e Ivan Amorosino do Amaral. Parte dos resultados desse trabalho está publicada em Fracalanza (2004). Esse projeto teve financiamento do CNPq entre 2006 e 2008, e o relatório final foi apresentado em outubro de 2008 (FRACALANZA, 2008). Na sequência, tivemos o trabalho de Iniciação Científica de Thais Eberlin, sob orientação de Hilário Fracalanza e Jorge Megid Neto, com apoio da FAPESP. Resultados do trabalho foram publicados nas Atas do V Encontro Nacional de Pesquisa em Educação em Ciências (EBERLIN et al., 2005). O terceiro projeto foi realizado por Juliana Rink, que estudou os trabalhos apresentados nos quatro primeiros Encontros de Pesquisa em Educação Ambiental - EPEA (RINK, 2009).

Essas experiências sobre pesquisas de estado da arte em Educação Ambiental levaram o grupo FORMAR-Ciências a se envolver no início de 2008 com Grupos de Pesquisa de três outras instituições de ensino superior do estado de São Paulo (UNESP, Campus de Rio Claro, USP, Campus de Ribeirão Preto, e UFSCar) e estabelecer o projeto interinstitucional "A Educação Ambiental no Brasil: análise da produção acadêmica (dissertações e teses)" (FRACALANZA et al., 2008), cujos resultados preliminares serão comentados mais à frente. O projeto foi coordenado pelo professor Hilário Fracalanza até seu falecimento em 
janeiro de 2009, passando a ser coordenado desde então pelo professor Luiz Marcelo de Carvalho, da UNESP, Campus de Rio Claro.

Passaremos a tratar de algumas características e tendências da produção acadêmica em EA, ainda em fase de sistematização e análise preliminar. Os dados referem-se à produção científica brasileira no campo da EA publicada sob a forma de teses e dissertações e foram obtidos direta ou indiretamente a partir dos trabalhos de Fracalanza (2004; 2008), Eberlin et al. (2005), Lorenzetti e Delizoicov (2007) e Rink (2009), além de consultas complementares ao Banco de Teses da CAPES em setembro de 2009.

Como dissemos, o início formal da pós-graduação stricto sensu no Brasil, nas várias áreas de conhecimento, data de meados dos anos 1960. No campo da EA, o primeiro programa de pós-graduação no país foi o Mestrado em Educação Ambiental da Universidade Federal do Rio Grande (FURG), criado em 1994. O primeiro programa de Doutorado em Educação Ambiental foi criado em 2006, também na FURG.

Desde então, a produção na área é encontrada em aproximadamente 220 programas de mestrado ou doutorado, específicos em EA ou denominações similares, ou ainda em programas de áreas correlatas, como Educação, Saúde Pública, Engenharia, Ciências Agrárias, entre outras. Todos esses programas estão estabelecidos em cerca de 60 instituições acadêmicas distribuídas por todas as regiões geográficas do país, muito embora predominem a região Sudeste $(50 \%$ da produção) e a região Sul (30\%). As regiões Centro-Oeste, Nordeste e Norte ficam responsáveis por cerca de $10 \%, 8 \%$ e $2 \%$, respectivamente. Tal distribuição está em sintonia com a distribuição dos programas de mestrado e doutorado na área de EA ou áreas correlatas; revertê-la implica fortes incentivos para a expansão da pós-graduação fora do eixo Sudeste-Sul do país, em especial dos programas de doutorado, fomentadores e nucleadores de Grupos de Pesquisa nas regiões em que são instalados. Nota-se, contudo, no caso das pesquisas em Educação Ambiental, uma participação significativa das regiões Centro-Oeste e Nordeste, o que não ocorre na produção acadêmica em outras áreas, como Educação em Ciências, por exemplo, em que menos de 10\% da produção total do país distribui-se pelas regiões Centro-Oeste, Nordeste e Norte (MEGID NETO, 2007).

No período de 1981 a 2008, identificamos 2.641 dissertações e teses defendidas no campo da Educação Ambiental. Cerca de 90\% dos trabalhos correspondem a dissertações de mestrado.

Para a obtenção desse total foi utilizado principalmente o banco de teses da CAPES, com a palavra-chave "educação ambiental". Todavia, outras palavraschave também foram utilizadas de modo complementar, como "ambiente", 
"temática ambiental", "natureza", entre outras. Catálogos de teses ou bancos de dados de instituições de ensino superior também foram utilizados para o levantamento, em especial no período anterior a 1987, tendo em conta que o banco de teses da CAPES só disponibiliza informações a partir de 1987.

A recuperação desses dados é uma etapa demorada e laboriosa das pesquisas do tipo estado da arte. Embora o banco da CAPES tenha facilitado sobremaneira esse trabalho, as informações ali disponíveis não são suficientes para identificar toda a produção em uma determinada área. As atualizações desse banco são realizadas periodicamente, mas incorporam dados relativos a períodos anteriores ao da última atualização, o que obriga os pesquisadores a refazerem todo o levantamento desde 1987 após cada data de atualização. Também a falta de certa padronização dos resumos elaborados pelos respectivos autores, e das demais informações de referência sobre cada tese ou dissertação, faz com que tenham de ser utilizadas várias palavras-chave para a recuperação de dados. A cada palavra-chave utilizada, alguns milhares de referências são obtidos, às vezes dezenas de milhares, exigindo uma leitura intensa dos resumos e referências para a seleção de documentos de interesse, bem como uma comparação quase infindável de listagens para suprimir as repetições.

No campo da Educação Ambiental, as instituições de maior produção são a FURG (cerca de 10\%), a USP (8\%), a UFMT (7\%), a UFSC (6\%), a UFRGS (3\%) e a UFRJ (3\%). São cerca de 60 instituições produtoras, sem haver forte concentração em duas ou três. Isso reforça a necessidade de estudos do tipo estado da arte de modo a facilitar a divulgação dessa produção e favorecer suas contribuições para os processos e programas educativos escolares e não escolares, para a definição de políticas públicas em EA e para o planejamento e implementação de ações estratégicas e responsáveis nesse campo.

Se tomarmos a distribuição por áreas dos programas de pós-graduação aprovados pela CAPES, dados preliminares indicam que a produção em Educação Ambiental concentra-se na área de Educação, com cerca de 50\% de teses e dissertações defendidas nesses programas. Seguem-se programas da área de Engenharia (10\%), área Multidisciplinar da CAPES (10\%), área de Ciências Biológicas (7\%), Ciências Sociais Aplicadas (6\%), Ciências Agrárias (6\%) e área de Ensino de Ciências e Matemática (3\%). Dado o caráter multidisciplinar da Educação Ambiental, poderia se esperar uma participação maior dos programas alocados na área Multidisciplinar da CAPES. A participação dos programas de pós-graduação em Educação é muito intensa no tratamento das questões de EA e um estudo mais aprofundado desse aspecto seria bem interessante a fim de avaliar os impactos temáticos, epistemológicos e metodológicos dessa tendência na constituição e desenvolvimento do campo de pesquisa em EA. 
O Gráfico 1 apresenta o crescimento quantitativo da produção ano a ano.

Gráfico 1. Distribuição Anual das Teses e Dissertações Brasileiras em Educação Ambiental Defendidas no Período 1981-2008.

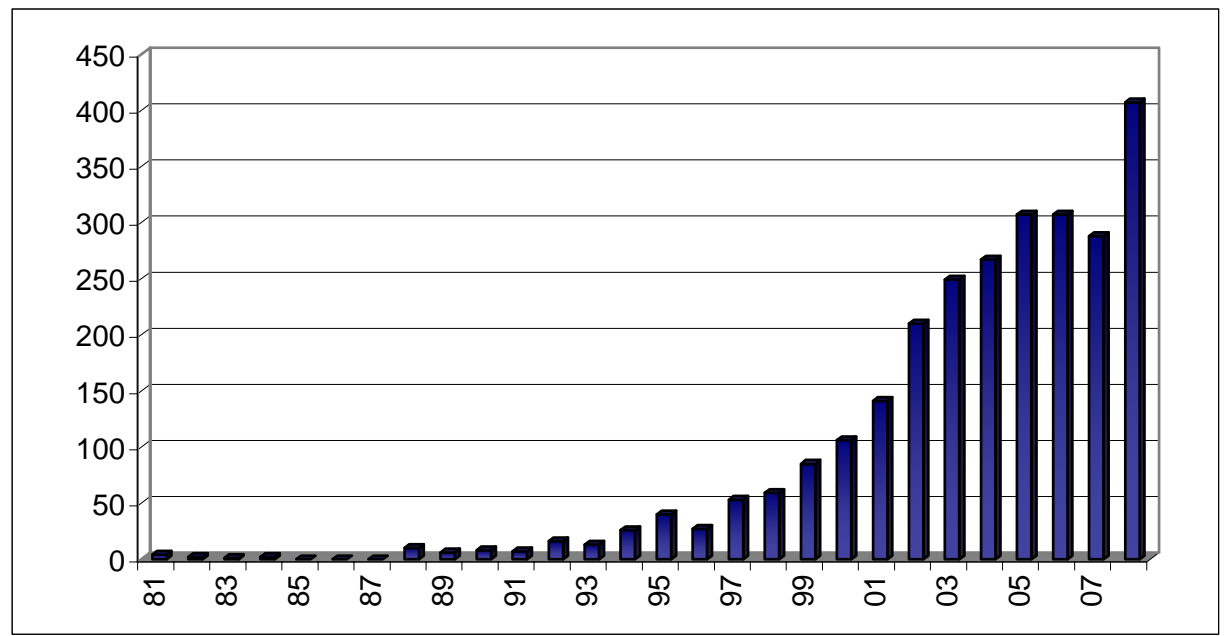

Fonte: Banco de Teses da CAPES, acesso em setembro de 2009; Eberlin (2005); Fracalanza (2008); Lorenzetti; Delizoicov (2007).

Como dissemos, em 1981 foram defendidas as 4 primeiras dissertações no campo da EA no Brasil. Ao longo da década de 1980, a produção foi muito pequena, havendo vários anos em que nenhum trabalho foi defendido na área. Ao final dessa década, e principalmente nos anos de 1990, a produção passa a ser mais regular, mostrando um crescimento cada vez mais intenso. No final da década de 1990, notamos um crescimento bastante vigoroso, pois a produção dobra a cada dois anos, aproximadamente: de 50 defesas/ano em 1997, passamos a 100 defesas/ano em 1999 e a 200 defesas/ano por volta de 2002. Essa taxa de crescimento aparentemente reflui nos anos seguintes, passando a 250 defesas/ano por volta de 2002/2003 e cerca de 300 defesas/ano em 2005/2007. Em 2008, nosso levantamento indica pouco mais de 400 dissertações e teses defendidas.

Os dados relativos aos últimos anos do período em questão ainda são preliminares, tendo em conta as atualizações periódicas realizadas pela CAPES em seu banco. É possível, assim, que o patamar aproximado no período 20052007 mostrado no Gráfico 1 transforme-se em crescimento contínuo quando os dados do presente levantamento estiverem consolidados. 
De qualquer modo, uma produção na faixa de 300 defesas/ano ou até mesmo acima de 400 defesas/ano, como em 2008, é um dado bastante significativo e bem superior a outros campos de pesquisa na área de Educação no Brasil. Como exemplo, a produção no campo da Educação em Ciências tem oscilado entre aproximadamente 200 e 300 defesas/ano desde o início dos anos 2000, praticamente nunca tendo ultrapassado a faixa de 300 defesas/ano, sendo essa área de pesquisa talvez a de maior expansão no cenário da pós-graduação brasileira entre as áreas específicas do campo da educação escolar. Claro que o fato de as pesquisas em Educação Ambiental envolverem também o contexto não escolar pode ser um dos fatores responsáveis por essa maior produção.

Quanto aos temas de investigação, estudos preliminares realizados até este momento indicam com maior frequência estudos voltados para levantamentos e análises de concep̧cões/representações/percepções de professores, agentes educadores ambientais, estudantes e público em geral, com aproximadamente $25 \%$ do total da produção, bem como trabalhos sobre métodos e estratégias de ensino envolvendo a relação conteúdo-método em EA, com cerca de $24 \%$ do total. Seguem-se os estudos abrangendo a formação inicial ou continuada de professores ou agentes educadores ambientais $(12 \%)$ e os estudos sobre formação $e$ desenvolvimento de conceitos em estudantes acerca de temas ou conteúdos pertinentes ao campo da EA (12\%).

De uma maneira geral, e ainda em estágio preliminar de análise, nota-se, no conjunto da produção em EA, uma participação pequena de estudos que articulam os conhecimentos de várias áreas na perspectiva interdisciplinar, bem como de estudos que buscam a solução de problemas locais e a transformação da realidade, próprios de investigações acadêmicas do tipo pesquisa-ação crítica ou pesquisa participante.

\section{O Projeto Interinstitucional “A Educação Ambiental no Brasil: análise da produção acadêmica (dissertações e teses)"}

Em vista das características e tendências da produção acadêmica brasileira no campo da Educação Ambiental apontadas anteriormente, o projeto em tela reveste-se de grande importância para identificar e descrever as características e tendências dessa relevante produção, bem como para analisar e avaliar aspectos particulares das pesquisas na área.

Nesse sentido, em 2008, quatro Grupos de Pesquisa, vinculados respectivamente à Unicamp, à UNESP (Campus de Rio Claro), à USP (Campus de Ribeirão Preto) e à UFSCar, reuniram-se com o intuito de constituir o projeto "A Educação Ambiental no Brasil: análise da produção acadêmica (dissertações e 
teses)" e buscar financiamento junto à FAPESP na categoria "Projeto Temático", linha de fomento para pesquisas estratégicas e de excelência no cenário científico e tecnológico do país ${ }^{2}$.

O projeto tem os seguintes objetivos:

a) recuperar os documentos que constituem a produção acadêmica e científica sobre Educação Ambiental no Brasil e organizar um acervo dos documentos referenciados (dissertações e teses);

b) classificar os documentos referenciados conforme descritores apropriados e produzir catálogos analíticos da produção;

c) identificar algumas das lacunas existentes na produção acadêmica e científica na área, as quais permitirão o incentivo à produção de novos estudos;

d) divulgar as informações obtidas mediante o emprego de diferentes mídias;

e) descrever e analisar os documentos obtidos produzindo estudos do tipo "estado da arte" conforme focos especificados;

f) colaborar com a definição de políticas públicas sobre Educação Ambiental e sobre a pesquisa nessa área.

A primeira fase do projeto está em andamento, consistindo na identificação e recuperação das teses e dissertações, no estabelecimento de descritores apropriados para a classificação desse material, na execução da classificação e na elaboração de catálogo analítico dessa produção.

$\mathrm{Na}$ segunda fase, ocorrerão os estudos mais específicos sobre a produção, tendo sido estabelecidos quatro temas de investigação: educação ambiental e formação continuada de professores da educação básica; processos de ambientalização curricular; concepções de educação ambiental; intersecção do ensino de ciências naturais com a educação ambiental.

Após várias reuniões de estudo e discussão e de exercícios preliminares de classificação, e tendo por base alguns trabalhos do tipo estado da arte (EBERLIN et al., 2005; FRACALANZA, 2008; MEGID NETO, 1998), a equipe do projeto consolidou a ficha de classificação e os respectivos descritores. Em seguida, deu-se início ao processo de classificação dos trabalhos,

2 Os Grupos de Pesquisa estão vinculados respectivamente: ao Departamento de Ensino e Práticas Culturais da Faculdade de Educação da Unicamp (grupo FORMAR-Ciências); ao Departamento de Educação do Instituto de Biociências da UNESP - Campus de Rio Claro (grupo A Temática Ambiental e o Processo Educativo); ao Departamento de Psicologia e Educação da Faculdade de Filosofia, Ciências e Letras da USP - Campus de Ribeirão Preto (LAIFE - Laboratório Interdisciplinar de Formação do Educador); ao Departamento de Metodologia de Ensino do Centro de Educação e Ciências Humanas da UFSCar. O projeto foi coordenado pelo Prof. Hilário Fracalanza (FEUnicamp) até janeiro de 2009, ocasião de seu triste falecimento; a partir de março de 2009, passou a ser coordenado pelo Prof. Luiz Marcelo de Carvalho (UNESP-Rio Claro). 
simultaneamente à continuidade do processo de identificação e recuperação de novas referências.

A ficha de classificação foi dividida em 5 campos principais. No primeiro campo, encontram-se os descritores de natureza (base) institucional de cada tese ou dissertação: autor, orientador, local de defesa, ano, grau acadêmico, nome do programa de pós-graduação, entre outros aspectos, conforme podemos observar no extrato a seguir dessa ficha.

Quadro 1. Extrato da Ficha de Classificação do Projeto “A Educação Ambiental no Brasil: análise da produção acadêmica (dissertações e teses)". Descritores da Base Institucional.

\begin{tabular}{|c|c|c|c|c|}
\hline Autor & & & Código & \\
\hline Orientador & & & Ano & \\
\hline Instituição & Sigla da IES & $\begin{array}{c}\text { Unidade/Setor (Sigla ol } \\
\text { nome) }\end{array}$ & Cidade & Estado \\
\hline \multicolumn{5}{|l|}{$\begin{array}{l}\text { Programa } \\
\text { de Pós- } \\
\text { Graduação }\end{array}$} \\
\hline \multirow{2}{*}{$\begin{array}{c}\text { Grau de } \\
\text { titulação } \\
\text { acadêmica }\end{array}$} & $\begin{array}{l}\text { Mestrado } \\
\text { Acadêmico }\end{array}$ & Mestrado Profissional & Doutorado & $\begin{array}{l}\text { Livre- } \\
\text { Docência }\end{array}$ \\
\hline & & & & \\
\hline
\end{tabular}

Fonte: Carvalho et al. (2009).

O segundo campo da ficha apresenta os descritores relativos ao Contexto Educacional, divididos em três grandes grupos: contexto escolar, quando a pesquisa envolve estudos ou ações relativas a um ou mais níveis escolares; contexto não escolar, quando a pesquisa lida com ações ou estudos de educação ambiental em espaços não formais de ensino; abordagem genérica, quando a pesquisa não trata explicitamente da educação ambiental no contexto escolar ou não escolar. Observemos esse campo e seus descritores no Quadro 2. 
Quadro 2. Extrato da Ficha de Classificação do Projeto "A Educação Ambiental no Brasil: análise da produção acadêmica (dissertações e teses)". Descritores do Contexto Educacional.

\begin{tabular}{|c|c|c|c|c|c|c|c|c|}
\hline \multirow{3}{*}{$\begin{array}{l}\text { Contexto } \\
\text { Educacional }\end{array}$} & Escolar & $\begin{array}{c}\text { Educ. } \\
\text { Infantil }\end{array}$ & $\begin{array}{c}E F \\
1^{\text {a }} \text { a } 4^{a}\end{array}$ & $\begin{array}{c}E F \\
5^{\mathrm{a}} \text { a } 8^{\mathrm{a}}\end{array}$ & $\begin{array}{l}\text { Ensino } \\
\text { Médio }\end{array}$ & $\begin{array}{c}\text { Educ. } \\
\text { Superior }\end{array}$ & E.J.A. & $\begin{array}{c}\text { Abordagem } \\
\text { Genérica } \\
\text { dos Níveis } \\
\text { Escolares }\end{array}$ \\
\hline & $\begin{array}{l}\text { Não } \\
\text { Escolar }\end{array}$ & \multicolumn{7}{|c|}{ (Obs.: Indicar tipo de público envolvido) } \\
\hline & $\begin{array}{c}\text { Abordagem } \\
\text { Genérica }\end{array}$ & & & & & & & \\
\hline
\end{tabular}

Fonte: Carvalho et al. (2009).

O terceiro campo da ficha traz os descritores da área de conhecimento ou área curricular abrangida pela pesquisa. Esse campo foi um dos que mais trouxeram dificuldades para a equipe na sua elaboração, em virtude do caráter multidisciplinar do campo de pesquisa em EA. Após várias versões, chegamos a uma formulação que entrelaça as áreas de conhecimento estabelecidas no CNPq e na FAPESP e também as áreas curriculares da educação básica, tendo sido realizadas algumas adaptações ou supressões tendo em conta o material a ser classificado. Ao longo do processo de classificação, pode ser que venhamos a fazer mais algumas alterações nesse campo. Observemos o resultado atual no Quadro 3.

Quadro 3. Extrato da Ficha de Classificação do Projeto "A Educação Ambiental no Brasil: análise da produção acadêmica (dissertações e teses)". Descritores da Área de Conbecimento/ Área Curricular.

\begin{tabular}{|c|c|c|c|c|c|c|c|}
\hline \multirow{2}{*}{$\begin{array}{c}\text { Área de } \\
\text { Conhecimento/ } \\
\text { Área Curricular }\end{array}$} & $\begin{array}{c}\text { Ciências } \\
\text { Agrárias }\end{array}$ & Artes & $\begin{array}{c}\text { Ciências } \\
\text { Biológicas }\end{array}$ & $\begin{array}{c}\text { Ciências da } \\
\text { Computação }\end{array}$ & $\begin{array}{c}\text { Ciências } \\
\text { Geológicas }\end{array}$ & $\begin{array}{c}\text { Ciências } \\
\text { Naturais }\end{array}$ & $\begin{array}{c}\text { Comunic. } \\
\text { e } \\
\text { Jornalismo }\end{array}$ \\
\cline { 2 - 8 } & História & $\begin{array}{c}\text { Língua } \\
\text { Estrangeira }\end{array}$ & $\begin{array}{c}\text { Língua } \\
\text { Portuguesa }\end{array}$ & Matemática & Química & Saúde & Sociologia \\
\cline { 2 - 8 } & Fúsica & Filosofia & Física & Geografia \\
\cline { 2 - 8 } & Turismo & \multicolumn{2}{|c|}{ GERAL } & \multicolumn{3}{|c|}{ OUTRA ÁREA (citar abaixo) } \\
\hline
\end{tabular}

Fonte: Carvalho et al. (2009).

O quarto campo, apresentado no Quadro 4, traz referência ao tema do campo da Educação Ambiental abordado na dissertação ou tese, por exemplo: 
sustentabilidade; áreas de preservação; desmatamento; resíduos sólidos; aquíferos; aquecimento global, entre outras possibilidades de conteúdos ou assuntos. A partir desse campo e ao final do processo de classificação, poderemos ter uma relação de temas comumente abordados nas pesquisas da área e sua frequência. Por ora, não estabelecemos temas específicos nesse campo (descritores específicos e subdivisões do quadro) à espera da diversidade de temas que aparecerá no conjunto das dissertações e teses. Podemos prever a necessidade de aglutinação dos temas, caso a diversidade seja muito grande.

Quadro 4. Extrato da Ficha de Classificação do Projeto "A Educação Ambiental no Brasil: análise da produção acadêmica (dissertações e teses)". Descritores do Tema Ambiental.

\section{Tema Ambiental} (citar)

Fonte: Carvalho et al. (2009).

Por último, apresentamos no Quadro 5 a relação de descritores para o foco temático de investigação, adaptados pela equipe do projeto a partir de trabalhos similares mencionados anteriormente. Esses focos estão associados às questões de investigação das pesquisas, denotando assim os principais problemas do campo da Educação Ambiental que vêm sendo estudados pelas teses e dissertações. Alguns dos focos serão objeto de estudos analíticos específicos na segunda fase do projeto.

Quadro 5. Extrato da Ficha de Classificação do Projeto "A Educação Ambiental no Brasil: análise da produção acadêmica (dissertações e teses)". Descritores do Foco Temático de Investigação.

\begin{tabular}{|c|c|c|c|c|c|}
\hline \multirow{3}{*}{$\begin{array}{c}\text { Foco } \\
\text { Temático }\end{array}$} & $\begin{array}{l}\text { Currículos, } \\
\text { Programas e } \\
\text { Projetos }\end{array}$ & $\begin{array}{l}\text { Conteúdo e } \\
\text { Métodos }\end{array}$ & $\begin{array}{l}\text { Recursos } \\
\text { Didáticos }\end{array}$ & $\begin{array}{l}\text { Concepções/Represen- } \\
\text { tações/Percepções do } \\
\text { Formador em EA }\end{array}$ & $\begin{array}{l}\text { Concepções/Represen- } \\
\text { tações/Percepções do } \\
\text { Aprendiz em EA }\end{array}$ \\
\hline & $\begin{array}{l}\text { Formação de } \\
\text { Conceitos }\end{array}$ & $\begin{array}{c}\text { Políticas } \\
\text { Públicas em } \\
\text { EA }\end{array}$ & $\begin{array}{l}\text { Organização } \\
\text { da } \\
\text { Instituição } \\
\text { Escolar }\end{array}$ & $\begin{array}{c}\text { Organização } \\
\text { Governamental }\end{array}$ & $\begin{array}{c}\text { Organização } \\
\text { Não Governamental }\end{array}$ \\
\hline & $\begin{array}{c}\text { Trabalho e } \\
\text { Formação de } \\
\text { Profs./Agentes }\end{array}$ & $\begin{array}{l}\text { Mov.Sociais/ } \\
\text { Mov. } \\
\text { Ambientalista }\end{array}$ & \multicolumn{3}{|c|}{ OUTRO FOCO (citar) } \\
\hline
\end{tabular}

Fonte: Carvalho et al. (2009). 
Os descritores do foco temático de investigação constituídos não contemplam todas as áreas ou temas de investigação nem apresentam uma estruturação lógica ou hierárquica. Alguns indicam temáticas mais abrangentes com respeito à Educação Ambiental no contexto escolar ou não escolar; outros são mais específicos, voltados para o processo de ensino-aprendizagem no âmbito escolar ou para processos educativos em espaços não escolares. Os focos constituídos têm naturezas distintas ou possuem fronteiras que permitem sobreposições entre si. Ao longo do processo de classificação, poderemos realizar um refinamento do conjunto desses descritores, e outros não previstos inicialmente poderão surgir.

Por essas razões, boa parte dos documentos poderá ser classificada em dois ou três focos temáticos; em alguns casos até mais, dada a abrangência ou a dispersão de assuntos tratados nas pesquisas em Educação Ambiental. Via de regra, o mesmo pode ocorrer com os demais campos da ficha de classificação e respectivos descritores.

A classificação de cada documento (dissertação ou tese) está sendo realizada por dois pesquisadores independentes (duplo-cego). No caso de divergência de classificação, ambos os pesquisadores se reúnem para chegarem a um resultado comum. O processo de classificação vem sendo realizado com base na leitura transversal do texto integral de cada dissertação ou tese e às vezes na leitura integral de algumas partes do trabalho. Isso tem sido um processo bastante demorado, além de ser dificultado pela demora na obtenção do texto integral das pesquisas, uma vez que uma pequena parcela (menos de 20\%) está disponível em formato eletrônico em bibliotecas digitais das instituições produtoras.

Embora a CAPES tenha exigido que a partir de 2006 todos os programas de pós-graduação de qualquer área disponibilizassem o texto integral das teses e dissertações ali defendidas, isso não está ocorrendo com a grande maioria dos programas. A obtenção dos documentos junto aos respectivos autores também tem um retorno muito baixo. Tem nos restado a obtenção dos documentos por intermédio do COMUT (Comutação entre Bibliotecas), o que, além de bastante oneroso para o projeto, apresenta um tempo de espera de até 6 meses.

Todas essas dificuldades são apontadas em estudos similares há mais de dez anos - por exemplo, em Megid Neto (1999). Ou seja, embora tenhamos observado uma sensível expansão da pós-graduação no país, com crescimento quantitativo da produção muitas vezes exponencial em várias áreas, o acesso aos documentos completos e aos resultados e contribuições dos estudos ainda é bastante precário no país. Tem-se produzido muito e cada vez mais em centros 
espalhados por todo o país, mas o acesso à produção e sua ampla e democrática socialização ainda são localizados, limitados e bastante restritos.

\section{Considerações Finais}

Além dos comentários anteriores sobre as dificuldades de acesso público e irrestrito aos textos integrais das teses e dissertações e sobre a carência de bancos digitais de informação seguros, completos e atualizados, fenômeno que alcança praticamente todas as áreas da pós-graduação no Brasil, devemos estar alertas para a perspectiva analítico-avaliativa dessa produção acadêmica. Não basta saber que o campo de pesquisa em Educação Ambiental cresceu vertiginosamente na última década em nosso país. Não basta saber que a cada dia uma ou duas dissertações/teses são defendidas em alguma instituição acadêmica deste país. Temos de avaliar a qualidade dessa produção, a consistência científica do conjunto dos trabalhos, a coerência entre propósitos de investigação e delineamentos metodológicos. E, sobretudo, temos de conhecer e avaliar a capacidade dessa produção em estudar os problemas ambientais locais e visar a mudança de realidade, em intervir e contribuir na formulação de políticas públicas consequentes e responsáveis no âmbito das questões ambientais, em intervir e produzir uma Educação Ambiental de natureza crítica e emancipatória.

Ter acesso à produção e conhecer suas principais características e tendências é somente um pequeno passo, necessário e imprescindível, sem dúvida, mas de forma alguma suficiente. Além de sabermos o que se produz em EA no Brasil, precisamos saber para qual Educação Ambiental essa produção tem se direcionado: nas palavras de Leff (2001), se para uma EA que visa a sustentabilidade global e (neo)liberal, ou se para uma EA que institui uma nova ética para a sustentabilidade e para a equidade social.

\section{Referências}

CACHAPUZ, António; GIL-PÉREZ, Daniel; CARVALHO, Ana Maria Pessoa; PRAIA, João; VILCHES, Amparo. A emergência da didáctica das Ciências como campo específico de conhecimentos. In: CACHAPUZ, Antonio et al. (Org.). A necessária renovação do ensino das Ciências. São Paulo: Cortez, 2005. p. 187-232.

CARVALHO, Luiz Marcelo de. A temática ambiental e a escola de $1^{\circ}$ Grau. São Paulo, 1990. Tese (Doutorado em Educação) - Faculdade de Educação, Universidade de São Paulo, São Paulo, 1990. 
CARVALHO, Luiz Marcelo de; TOMAZELLO, M.G.C.; OLIVEIRA, Haydée Torres de. Pesquisa em Educação Ambiental: panorama da produção brasileira e alguns de seus dilemas. Cad. CEDES, Campinas, v. 29, n. 77, p. 13-27, jan./abr. 2009.

CARVAlHO, Luiz Marcelo de et al. Projeto A Educação Ambiental no Brasil: análise da produção acadêmica (dissertações e teses). Rio Claro/SP: UNESP/Unicamp/USP/ UFSCar, março de 2009.

EBERLIN, Thais et al. A Educação Ambiental no Brasil: panorama inicial da produção acadêmica. In: ENCONTRO NACIONAL DE PESQUISA EM EDUCAÇÃO EM CIÊNCIAS, 5., 2005, Bauru. Anais... Bauru: ABRAPEC, 2005. (CD-ROM).

FÁVERO, Osmar. A trajetória da pós-graduação em educação no âmbito institucional. In: ANPEd. Avaliação e perspectivas na área de educação: 1982-91. Porto Alegre: ANPEd, 1993. p. 31-49.

FERNANDES, Rebeca C. A. Tendências da pesquisa acadêmica sobre o ensino de Ciências nas séries iniciais da escolarização (1972-2005). 2009. Dissertação (Mestrado em Educação) Faculdade de Educação, Universidade Estadual de Campinas, 2009.

FRACALANZA, Hilário. O que sabemos sobre os livros didáticos para o ensino de ciências no Brasil. 1993. 302 f. Tese (Doutorado em Educação) - Faculdade de Educação, Universidade Estadual de Campinas, Campinas, 1993.

As pesquisas sobre Educação Ambiental no Brasil e as escolas: alguns comentários preliminares. In: TAGLIEBER, José Erno; GUERRA, Antonio Fernando Silveira (Org.). Pesquisa em Educação Ambiental: pensamentos e reflexões de pesquisadores em Educação Ambiental. Pelotas: Universitária, 2004.

. (Coord.) O que sabemos sobre a Educação Ambiental (EA) no Brasil: análise da produção acadêmica. Relatório do Projeto CNPq, Processo 401289/2005-0, out. 2008.

FRACALANZA, Hilário et al. Projeto A Educação Ambiental no Brasil: análise da produção acadêmica (dissertações e teses). Campinas/SP: Unicamp/UNESP/USP/UFSCar, ago. 2008.

LEFF, Enrique. Educação Ambiental e desenvolvimento sustentável. In: REIGOTA, Marcos (Org.). Verde cotidiano: o meio ambiente em discussão. 2. ed. Rio de Janeiro: DP\&A, 2001. p. 111-129. (Coleção O sentido da escola).

LORENZETTI, Leonir; DELIZOICOV, Demetrio. A produção acadêmica brasileira em educação ambiental. Pré-publicação: CONGRESO CEISAL, 5., Bruselas, 11-14 abr. 2007. Disponível em: <http://www.reseau-amerique-latine.fr/index.php?act=busc\&result= actu\&multi=lorenzetti $>$. Acesso em: 09 jul. 2007.

MEGID NETO, Jorge. Pesquisa em ensino de Física do $2^{\circ}$ grau no Brasil: concepção e tratamento de problemas em teses e dissertações. 1990. 296 f. Dissertação (Mestrado em Educação) - Faculdade de Educação, Universidade Estadual de Campinas, Campinas, 1990.

(Coord.). O ensino de Ciências no Brasil: catálogo analítico de teses e dissertações, 1972 1995. Campinas: Unicamp/FE/CEDOC, 1998. 220 p.

Tendências da pesquisa acadêmica sobre o ensino de Ciências no nível fundamental. 1999.

Tese (Doutorado em Educação) - Faculdade de Educação, Universidade Estadual de Campinas, Campinas, 1999.

- Três décadas de pesquisas em Educação em Ciências: tendências de teses e dissertações (1972-2003). In: NARDI, R. (Org.). A pesquisa em ensino de Ciências no Brasil: alguns recortes. São Paulo: Escrituras, 2007. p. 341-355.

NOGUEIRA, Marilac Luzia de Souza Leite S. Práticas interdisciplinares nas séries iniciais do ensino fundamental: um estudo de teses e dissertações. 2008. Dissertação (Mestrado em 
Educação) - Faculdade de Educação, Universidade Estadual de Campinas, Campinas, 2008.

REIGOTA, Marcos. O Estado da arte da pesquisa em Educação Ambiental no Brasil. Pesquisa em Educaşão Ambiental, Ribeirão Preto, v. 2, n. 1, p. 33-66, jan./jun. 2007.

RINK, Juliana. Análise da produção acadêmica apresentada nos Encontros de Pesquisa em Educação Ambiental (EPEA). 2009. Dissertação (Mestrado em Educação) - Faculdade de Educação, Universidade Estadual de Campinas, Campinas, 2009.

SANTOS, Edilson Duarte dos. A experimentação no ensino de ciências de $5^{a}$ a $8^{a}$ séries do ensino fundamental: tendências da pesquisa acadêmica entre 1972 e 1995. 2001. Dissertação (Mestrado em Educação) - Faculdade de Educação, Universidade Estadual de Campinas, Campinas, 2001.

SILVA, Regina Celia Pinheiro da. Pesquisas sobre formação de professores/educadores para abordagem da educação sexual na escola. 2004. Dissertação (Mestrado em Educação) Faculdade de Educação, Universidade Estadual de Campinas, Campinas, 2004.

TEIXEIRA, Paulo Marcelo Marini. Pesquisa em ensino de Biologia no Brasil (1972-2004): um estudo baseado em dissertações e teses. 2008. Tese (Doutorado em Educação) Faculdade de Educação, Universidade Estadual de Campinas, Campinas, 2008.

Artigo: recebido em 17/11/2009 - aprovado em 21/12/2009 